\title{
Who shares health and medical scholarly articles on Facebook ${ }^{1}$
}

\author{
Ehsan Mohammadi* \\ Nilofar Barahmand ** \\ Mike Thelwall ${ }^{* \star *}$ \\ ${ }^{*}$ College of Information and Communications, University of South Carolina, Columbia, South Carolina, United States \\ of America.https://orcid.org/0000-0001-6065-205X. **Scientometrics Division, Shiraz University of Medical Sciences, \\ Shiraz, Iran.https://orcid.org/0000-0002-2489-8025 ***Statistical Cybermetrics Research Group, School of \\ Mathematics and Computer Science, University of Wolverhampton, Wolverhampton, UK. https://orcid.org/0000- \\ 0001-6065-205X
}

Over a million journal articles had been shared on public Facebook pages by 2017 , but little is known about who is sharing (posting links to) these papers and whether mention counts could be an impact indicator. This study classified users who had posted about 749 links on Facebook before October 2017 mentioning 500 medical and health-related research articles, obtained using altmetric.com data. Most accounts (68\%) belonged to groups, including online communities, journals, academic organizations, and societies. Of individual profiles, academics accounted for only $4 \%$, but the largest group were health care professionals (16\%). More than half $(58 \%)$ of all Facebook accounts examined were not academic. The non-academic dominance suggests that public Facebook posts linking to health-related articles are mostly used to facilitate scientific knowledge flow between nonacademic professionals and the public. Therefore, Facebook mention counts may be a combined academic and non-academic attention indicator in the health and medical domains.

\section{Introduction}

Disseminating scientific results beyond research fields is important for issues such as public awareness, clinical applications (Sarli \& Holmes, 2012), and educational support (Kousha \& Thelwall, 2016). Moreover, even if journal articles are freely shared online, their length, structure and jargon may make them inaccessible to a lay audience. While the science communication dissemination function has previously been the domain of scientific magazines, newspaper science sections and professional magazines, the social web is now routinely used to share scholarly information. Since a large section of the population uses the social web (e.g., $69 \%$ of US adults were on Facebook in 2019 (Perrin \& Anderson, 2019), it may be useful for disseminating research to the public. This could either be through publicity (linking to articles) or translation (explaining results to non-specialists). Despite Facebook having been one of the most popular social web sites for over a decade, relatively little science communication research about it has been carried out (Enkhbayar, Haustein, Barata, \& Alperin, 2019).

From a different perspective, while citation-based indicators are often used by academics to track the scholarly impact of research, they do not reflect non-academic impacts (MacRoberts \& MacRoberts, 1989) and so other methods are also needed (HEFCE, 2019; NIH, 2019). Social web mentions (altmetrics) have been proposed as indicators for this, although thorough evaluations are needed before they can be used.

Several quantitative studies have explored social media mentions of academic publications but found only weak positive associations or correlations between citation counts and mentions of journal articles on Facebook, Twitter, and blogs (Thelwall, Haustein, Larivière, \& Sugimoto, 2013; Shema, Bar-llan, \& Thelwall, 2014). This indicates that such social media mentions might provide some indication of scholarly or social impact but to interpret the meaning of the counts it is important to know who creates social web citations (Sud \& Thelwall, 2014). Previous studies have found that about half of the users who disseminate academic information on Twitter are non-academics (Mohammadi, Thelwall, Kwasny, \& Holmes, 2018; see also: Didegah, Mejlgaard, \& Sørensen, 2018; Tsou, Bowman, Ghazinejad, \& Sugimoto, 2015) and that users who bookmark journal articles in the social reference sharing website Mendeley tend to be junior researchers (Mohammadi, Thelwall, \& Kousha, 2016).

Previous studies have found weak associations between citation counts and Facebook mentions of journal articles (Haustein, Costas, \& Larivière, 2015), suggesting that Facebook

\footnotetext{
${ }^{1}$ This is the accepted version of the following article: Mohammadi, E., Barahmand, N. \& Thelwall, M. (in press). Who shares health and medical scholarly articles on Facebook? Learned Publishing, doi: 10.1002/leap.1271, which has been published in final form at [Link to final article].
} 
mentions are not good indicators of scholarly impact (i.e., within academia), however they may provide indicators of societal impact. Identifying the Facebook users that post links to academic research can help to understand the context of these posts and the type of impact, if any, that they reflect (Sud \& Thelwall, 2014). For example, whether sharing is simply a promotional activity (e.g. journals sharing their recent articles), , or an indicator of outreach (e.g. a non-academic mentioning an article).

This study addresses this gap by identifying the types of users who disseminate health and medical journal articles on Facebook. Health and medical journal articles were selected because they are shared (i.e., a Facebook post with a link to the article) on Facebook more than articles from other fields (Haustein et al., 2015), and this type of research has a natural audience within the public and among health professionals. This paper uses public Facebook pages, focusing on broadcast type of dissemination, since private Facebook pages are not available to research on a large scale, their data is not used for article impact monitoring, and they may reflect a different, more personal, type of communication.

\section{Literature Review}

\section{Facebook and scholarly communication}

Social network sites are an integral part of the social web, providing useful facilities to create and share scientific information (Nentwich \& König, 2014). Facebook is one the most popular social network websites, with many users in academic settings ( (Bowman, 201; Madhusudhan, 2012; Moran, Seaman, Group, \& 2011). It is not clear whether academics use Facebook for their personal networking or professional use, although an online convenience sample survey found that $25 \%$ of scholars and Ph.D. students in England used Facebook only for professional activities (Procter et al., 2010). A survey of 1,639 faculty members from 62 universities in the Association of American Universities list revealed that $70 \%$ had Facebook accounts (Bowman, 2015). A qualitative study of professors in Spanish universities found that they used Facebook for personal activities, to create focused research groups and to connect with students (Segado-Boj, Díaz-Campo, Fernández-Gómez, \& Chaparro-Domínguez, 2019). Organizations can also use Facebook to share scholarly information. Kortelainen and Katvala (2012) studied journals with high impact factors in different areas, finding that $9 \%$ had a Facebook profile. In contrast, a another study found that $80 \%$ of journals with high Journal Impact Factors in general medicine had a Facebook presence (Kamel Boulos \& Anderson, 2012). Similarly, Zedda and Barbaro (2015) discovered that most Science, Technology, and Medicine publishers (80\%) posted links to their articles on Facebook. Uptake of Facebook is uneven internationally, however. Alperin (2015) found that only $3 \%$ of journal articles from SciELO, the Latin American journal portal had presences on Facebook.

At the level of individual articles, an analysis of half a million journal articles found that $2.5 \%$ were shared on public Facebook pages (Costas, Zahedi, \& Wouters, 2015). Another study found that only $4.7 \%$ of 1.3 million articles published in 2012 were publicly mentioned on Facebook (Haustein et al., 2015). Given the low overall percentages, it seems likely that the coverage of journal articles on Facebook varies based on publication type, discipline, language, and geography. Additionally, the methods for tracking scientific publications on Facebook may differ from one altmetric data provider to another (Zahedi, Fenner, \& Costas, 2014).

From a statistical perspective, very low correlations have been found between citation counts and Facebook mentions for journal articles indexed in PubMed (Thelwall et al., 2013), articles across different disciplines covered by Web of Science (Zahedi, Costas, \& Wouters, 2014; Costas et al., 2015; Haustein et al., 2015), and Public Library of Science publications (Barthel, Tönnies, Köhncke, Siehndel, \& Balke, 2015). However, there are slightly stronger correlations between Facebook mentions of scientific journal articles, and blog and news platform mentions (Haustein et al., 2015). Another study revealed that Facebook mentions can be considered as an early impact indicator for journal articles in psychology but not in other areas, including business (Ringelhan, Wollersheim, \& Welpe, 2015). Thus, it is not clear whether counting Facebook mentions of scientific publications would provide useful information about their public or academic impact.

\section{Audiences for academic publications}

A wide range of people uses scholarly information within academia for different purposes, including learning, research, and teaching (King, Tenopir, Choemprayong, \& Wu, 2009). For example, Ph.D. students read and cite more articles than other academics (Mohammadi, Thelwall, Haustein, \& Larivière, 2015; Larivière, Sugimoto, \& Bergeron, 2013). Non-publishing individuals, such as undergraduates, and 
teaching-only lecturers also use academic resources in teaching and learning activities (Mohammadi, Thelwall, \& Kousha, 2016; Kousha \& Thelwall, 2008).

Some people outside academia also read journal articles, with aims that vary between jobs and contexts. For instance, some professionals read scientific journal articles to help with their day-to-day tasks (Bollen \& Sompel, 2008). Pediatricians read research articles to be updated about new trends in the field (Tenopir, King, Clarke, Na, \& Zhou, 2007), and more than $70 \%$ of medical doctors in Canada use scientific papers (McAlister, Graham, Karr, \& Laupacis, 1999). Doctors-in-training also use journal articles during their residency (Schilling, Steiner, Lundahl, \& Anderson, 2005).

\section{Sharing scientific publications on the social web}

Some information is known about who posts academic information on the social web, but mainly for Twitter. A content analysis of 2000 Twitter profiles of users who tweeted journal articles found that three quarters were individual (76\%) rather than institutional accounts (Tsou et al., 2015). A manual analysis of a random sample of 100 users who tweeted highly tweeted Finnish journal articles in different subjects found that scholars were the most common type of tweeter, but the pattern varied based on the subjects of the journal articles. For instance, healthcare professionals tended to tweet health and medical journal articles whereas institutional accounts were more likely to tweet social science and humanities journal articles (Vainio \& Holmberg, 2017). Using an automatic classification provided Altmetric.com, Yu (2017) found that more $85 \%$ of tweeters sharing scientific articles were members of the public. Altmetric.com's classifications of Twitter users are unreliable, however, because they apply "Member of the public" to profiles that cannot be fitted into other categories (i.e., researcher, practitioner, science communicator) (Altmeric LLP, 2017). Recently, a content analysis of Twitter users who disseminated academic articles reported that the types of users differed across different disciplines. In particular, $62 \%$ and $43 \%$ were individual public accounts for Physical \& Engineering and Social \& Humanities journal articles while 48\% and $37 \%$ of users who tweeted Math \& Computer and Social \& Humanities were scholars (Didegah et al., 2018). A survey of users who tweeted scholarly information confirmed that just over half $(55 \%)$ were in academia (Mohammadi et al., 2018).

The only relevant Facebook study found that members who posted psychology journal articles on Facebook reported that they were mainly not academic users (Na \& Ye, 2017).

\section{Methods}

A data dump from Altmetric.com from 2017 was used as the source of journal articles that had been posted about on Facebook. Altmetric.com scans public Facebook pages for evidence of links to journal articles, which it tracks through their Digital Object Identifiers (DOIs). Altmetric.com seemed likely to produce a reasonably comprehensive list of these Facebook mentions since it is experienced in this type of data gathering. This approach was deemed preferable to collecting the same data directly because some pages were old and the amount of data collection needed seemed too great for the current purpose of generating a large random sample.

The Altmetric.com dataset included 1,209,244 records with at least one Facebook mention. These were classified by subject with the Science-Metrix journal classification schema. This schema was chosen because it is an enhanced ontology based on several existing journal classifications and each journal is assigned to a single subject. Around $13 \%$ of the records were not found in the classification and these were discarded. These were typically from journals that had changed their name or were not judged important enough to include in the Science-Metrix schema.

The sample was limited to the $382,731(32 \%)$ journal articles in the Health Sciences domain in the Science-Metrix schema. Health Sciences journal articles were chosen as relating to an area with many potential professional and public users. The Health Sciences domain encompasses four main fields (Table 1).

Table 1. The total and sampled number of journal articles mentioned in public Facebook pages by October 2017, broken down by Science-Metrix health sciences subfield.

\begin{tabular}{|l|l|l|}
\hline Field & Frequency (\%) & Sample (\%) \\
\hline Clinical Medicine & $255,770(67 \%)$ & $334(67 \%)$ \\
\hline Biomedical Research & $60,336(16 \%)$ & $79(16 \%)$ \\
\hline Public Health \& Health Services & $43,997(11 \%)$ & $57(11 \%)$ \\
\hline Psychology \& Cognitive Sciences & $22,628(6 \%)$ & $30(6 \%)$ \\
\hline Total & $\mathbf{3 8 2 , 7 3 1}$ & $\mathbf{5 0 0}$ \\
\hline
\end{tabular}


To understand the types of users who post links to journal articles on Facebook, manual content analysis was chosen. This is a transparent method for identifying, analyzing, and reporting patterns and themes within data (Braun \& Clarke, 2006). Stratified random sampling with a random number generator was used to choose 500 journal articles from the four health sciences fields. Stratified sampling was used to ensure that the overall sample was representative of the four major fields. To develop the codebook for the content analysis, we initially used prior categories of users of academic publications based on available literature as a deductive approach. We also applied an inductive approach to extend and refine the codebook using content analysis of an initial stratified sample of 100 articles from the four subfields listed in Table 1. New categories were added when new types of user were encountered. This was repeated iteratively, reconsidering descriptions of categories and reassigning users to them whenever the categories were modified. This was continued until no new types of users were encountered and code descriptions no longer needed to be modified.

To ensure the reliability of the category descriptions, the initial sample was coded by two human coders, who resolved disagreements through discussion. A similar procedure has been used in previous research (Kalsnes \& Larsson, 2018). The final codebook consisted of four main categories, 11 subcategories, and definitions and examples of users.

For the main sample, 400 additional journal articles were selected using stratified sampling with a random number generator for each of the four subcategories. These were coded manually with the codebook in 2019.

Some journal articles in the sample were mentioned more than once on Facebook. Using the codebook, 955 Facebook links were checked for the sample of $500(=100+400)$ health sciences journal articles.

\section{Results}

The sample of 500 biomedical papers in this study was mentioned 955 times on Facebook. A fifth (21\%, $\mathrm{n}=206$ ) of the Facebook pages were not accessible due to privacy settings or deletion. This left 749 Facebook pages to analyze. The papers were mentioned a median of 2 times each, although some were mentioned more than 10 times.

This study found four main categories and 11 subcategories of users (Table 2). Descriptions of the categories are given in the codebook. Overall, $58 \%(n=431)$ of members sharing journal articles on Facebook were non-academics.

Table 2. Facebook members that post links to academic health sciences journal articles, categorized by type.

\begin{tabular}{|c|c|c|c|c|c|}
\hline Category & Academic & Number/\% & Non-Academic & Number/\% & All \\
\hline \multirow{4}{*}{$\begin{array}{l}\frac{\omega}{\pi} \\
\frac{0}{2} \\
\frac{\partial}{2} \\
\frac{\partial}{0}\end{array}$} & \multirow[t]{3}{*}{ Academics } & \multirow[t]{3}{*}{$31(4 \%)$} & $\begin{array}{l}\text { Bloggers and Science } \\
\text { communicators }\end{array}$ & $46(6 \%)$ & \\
\hline & & & $\begin{array}{l}\text { Health care } \\
\text { Professionals }\end{array}$ & $121(16 \%)$ & \\
\hline & & & $\begin{array}{l}\text { Non-health care } \\
\text { professionals }\end{array}$ & $45(6 \%)$ & \\
\hline & Total & $31(4 \%)$ & Total & $212(28 \%)$ & $243(32 \%)$ \\
\hline \multirow{5}{*}{$\begin{array}{l}\frac{0}{\pi} \\
\frac{0}{2} \\
\frac{0}{2} \\
\frac{1}{0} \\
\frac{0}{1} \\
\frac{1}{2} \\
\frac{1}{2}\end{array}$} & $\begin{array}{l}\text { Academic and } \\
\text { educational } \\
\text { organizations }\end{array}$ & $92(12 \%)$ & Online communities & $129(17 \%)$ & \\
\hline & Journals & $108(14 \%)$ & \multirow{2}{*}{$\begin{array}{l}\text { Commercial and } \\
\text { Industrial organizations }\end{array}$} & \multirow[t]{2}{*}{$73(10 \%)$} & \\
\hline & \multirow[t]{2}{*}{$\begin{array}{l}\text { Associations and } \\
\text { societies }\end{array}$} & $87(12 \%)$ & & & \\
\hline & & & Other & $17(2 \%)$ & \\
\hline & Total & 287 (38\%) & Total & $219(29 \%)$ & 506 (68\%) \\
\hline All & \multicolumn{2}{|l|}{$318(42 \%)$} & \multicolumn{2}{|l|}{$431(58 \%)$} & \\
\hline
\end{tabular}

\section{Category Descriptions}

Examples of different categories can be found on FigShare (see: Mohammadi, Barahmand, Thelwall, 2019). 
Individual (32\%, $n=243)$ and non-individual users (68\%, $n=506)$ : A user is defined as an individual if a single person manages the Facebook account. Non-individuals include accounts maintained by more than one person or an organization.

Academics (4\%) are individuals working in an academic-related setting. Both researchers and faculty members are included such as professors, lecturers, and researchers. Academics may post for teaching, research or other purposes. Only $4 \%(n=31)$ of the sample were individual academics.

Academic and educational organizations $(12 \%, n=92)$ covers Facebook pages administrated by non-individuals such as universities, colleges and academic research centers and labs. This includes a few academic libraries. @uccollegeofnursing, a page for the University of Cincinnati College of Nursing, is an example of this category.

Journals $(14 \%, n=108)$ are Facebook members promoting a single journal's publications via their Facebook pages and presenting the profile of that journal. For instance, Cell (@CellCellPress) is in this category. The 108 articles with links posted by journals were manually checked for their publisher. Parent organizations were recorded, when relevant. For instance, Springer and Nature were both recorded as Springer Nature Publishing. Journals published by associations and societies, such as the American Medical Association, were recorded as Associations and Societies. Publishers with few articles were listed as Other. Elsevier, Associations and Societies publishers, Springer Nature Publishing, Wiley, and Wolters Kluwer were the most frequent publishers in the sample (Table 3).

Associations and societies $(12 \%, \mathrm{n}=87)$ are academic non-individual Facebook members. This group includes non-individuals that are recognized as official corporate bodies. The Facebook accounts need to mention the official website of the associations or societies. Nevertheless, it is hard to classify associations and societies as purely as academic organizations because some have both professional and academic responsibilities. @GeneticsGSA is an example of this category which is the Facebook account of the Genetics Society of America.

Table 3. Publishers of health and medical journal articles with links posted on Facebook via journal accounts.

\begin{tabular}{|l|c|}
\hline Publisher & $\begin{array}{c}\text { Number and \% of } \\
\text { articles in sample }\end{array}$ \\
\hline Elsevier & $29(27 \%)$ \\
\hline Associations and Societies publishers & $19(18 \%)$ \\
\hline Springer Nature Publishing & $17(16 \%)$ \\
\hline Wiley & $15(14 \%)$ \\
\hline Wolters Kluwer & $10(9 \%)$ \\
\hline Other publishers & $9(8 \%)$ \\
\hline Taylor and Francis & $3(3 \%)$ \\
\hline Thieme & $3(3 \%)$ \\
\hline SAGE & $3(3 \%)$ \\
\hline Total & $108(100 \%)$ \\
\hline
\end{tabular}

Bloggers and science communicators (6\%) are users that describe themselves as blog writers or scientific journalists in their Facebook profiles or on other information sources that they provided in their Facebook profiles, such as their Twitter accounts or blogs.

Health Care Professionals (16\%) are users who state that they work in clinical, medical or other health-related jobs such as physicians, clinical psychologists, dieticians, and physiotherapists. An example is a neurosurgeon who posted an academic paper on Facebook.

Non-Health Care Professionals (6\%) are users that are not Health Care Professionals but describe themselves in their Facebook profiles as experts in a range of professions such fitness and yoga instructors. They post academic articles related to their profession, to promote their services or products or as an information resource for their clients and audience. An example is in the supplementary materials. For instance, a yoga instructor shared an article on Facebook.

Online communities (17\%) covers any informally organized group of people that use Facebook as a platform to support or promote initiatives, movements and programs (cf. (Preece \& MaloneyKrichmar, 2005). These groups may be born online or in Facebook, or they may be face-to face communities. They can be professionals or lay persons who are interested or have concerns about the medical and health-related topics. Examples are COPD friends for friends, which is an online community for people with lung problems and their families. 
Commercial and industrial organizations $(10 \%)$ consisted mainly of organizations that produce, market or sell health related products. An example is in the supplementary materials. For instance, $@$ TrueHealth4u is the Facebook account of a company that posted a research paper.

Other non-academic organizations: Around $2 \%$ of the sample was classified as other nonacademic organizations. This category includes governmental agencies and health centers.

\section{Discussion and conclusions}

The results show that a wide range of individual and collective Facebook members inside and outside of academia share health and medical journal articles. Most of the articles were disseminated by nonacademic users (58\%), while large numbers of academic users (individuals and non-individuals) also posted links to health-related articles $(42 \%)$. This provides evidence that Facebook is a platform that people outside academia use to publicly disseminate scientific publications to the public and professional networks. These findings support claims from previous studies that social web sites like Facebook and Twitter can facilitate knowledge flows from academia to a broader audience (Na \& Ye, 2017; Mohammadi et al., 2018; Didegah et al., 2018).

Only a third of posters were individuals which supports previous findings for psychology ( $\mathrm{Na} \mathrm{\&}$ Ye, 2017). This suggests that the types of members who share journal articles on Facebook are different from Twitter, where the majority of tweeters are individuals (Haustein, Bowman, et al., 2014). This may be due to the ability to create a substantial permanent profile on Facebook in contrast to Twitter.

Of note is the fact that individual academics made only $4 \%$ of all postings while most of the individual users were professionals. Academics use social media for both professional and personal activities (Bowman, 2015) and may use Facebook mainly for personal activities. The fact that health care professionals are active in posting about articles may not be surprising because previous studies have shown that medical professionals use Facebook to communicate health care information with peers and patients (Bosslet, Torke, Hickman, Terry, \& Helft, 2011). This result also aligns with a study finding tweeters sharing scholarly information tended to be professionals rather than academic researchers (Haustein, 2019). This indicates that health-related scholarly information may be primarily posted by nonacademics on the social web more generally.

The largest group of posters were online communities which provide avenues for patients, families, and professionals to exchange health and medical information (Farmer, Holt, Cook, \& Hearing, 2009). Again, it is not surprising that this group are active in discussing and mentioning published articles within their discussions - but it is also reassuring that they are making use of academic articles in their discussions.

Because of the apparent non-academic interest and audience, Facebook seems more suitable for attracting a non-academic audience than social network sites like ResearchGate and Academia.edu, sites where many scholars often share articles. Therefore, the lack of academic sharing on Facebook may indicate that such a venue is of lower interest to academics than sharing with peers on other platforms which could be a lost opportunity to reach out to lay audiences. Increasingly, funders are hoping to measure societal impact of research and are starting to ask for outreach and measures of society impact which Facebook may facilitate (HEFCE, 2019). However, non-individuals such as associations and societies may be performing this role with their greater number of posts.

Academic organizations such as universities and academic journals use Facebook to promote their journal articles to scholars or beyond academia. This is unsurprising because the use of social media by journals and universities has been previously noted (Peruta \& Shields, 2017; Zedda \& Barbaro, 2015). Associations and societies are also using Facebook to share health and medical publications with their members. Again, this is unsurprising as social media use is prevalent in medical associations (Loeb et al., 2014).

These results also confirm that health sector businesses use Facebook to link to academic information, presumably as part of a strategy to promote their services and products by establishing their credibility to customers.

Since over half of the links to journal articles are from non-academic Facebook users, Facebook mention counts cannot be interpreted as academic impact indicators. It would also not be reasonable to view Facebook mention counts as a self-publicity indicators since postings from authors appears to be low. It is possible that Facebook mention counts could be indicators of a lay audience attention (if not impact) since most posters are not academics and it seems likely that a substantial proportion of the audience for these posts is also non-academic who may be assumed to be networked with other nonacademics (Efron, 2011). To claim Facebook mention counts as impact indicators, it would be necessary to identify that they led to tangible impacts, however. 
This study reveals that Facebook mentions of health and medical articles are made by a wide variety of users, with no single group dominating but with over half of users being non-academic users (both individual and institutional). Of particular note is the relatively low activity by academics, and the relatively high activity from health care professionals and online communities.

\section{Limitations}

This study is limited to health and medical journal articles and future efforts will be needed to assess the extent to which the findings also apply to other academic disciplines, such as the natural and social sciences and humanities. This study has several other limitations. The Altmetric.com data uses DOls to track social web mentions of journal articles. Other mentions will be missed, as will all private Facebook mentions. This is a significant limitation, as a recent study found that around half of the articles were shared privately on Facebook (Enkhbayar et al., 2019). During the coding process, no errors were found in the Altmetric.com data. However, the data set is limited to articles with DOIs.

\section{Supplementary materials}

Supplementary materials are published on Figshare.com. (see: Mohammadi, Barahmand, Thelwall, 2019).

\section{References}

Alperin, J. P. (2015). Geographic variation in social media metrics: An analysis of Latin American journal articles. Aslib Journal of Information Management, 67(3), 289-304. https://doi.org/10.1108/AJIM-12-2014-0176

Altmeric LLP. (2017). How are Twitter demographics determined? Retrieved from https://help.altmetric.com/support/solutions/articles/6000060978-how-are-twitter-demographics

Barthel, S., Tönnies, S., Köhncke, B., Siehndel, P., \& Balke, W.-T. (2015). What does Twitter Measure? - Influence of Diverse User Groups in Altmetrics. 15th ACM/IEEE Joint Conference on Digital Libraries (JCDL). https://doi.org/10.1145/2756406.2756913

Bollen, J., \& Sompel, H. Van de. (2008). Usage impact factor: The effects of sample characteristics on usage-based impact metrics. Journal of the American Society for Information Science and Technology, 59(1), 136-149. https://doi.org/10.1002/asi.20746

Bosslet, G. T., Torke, A. M., Hickman, S. E., Terry, C. L., \& Helft, P. R. (2011). The Patient-Doctor Relationship and Online Social Networks: Results of a National Survey. Journal of General Internal Medicine, 26(10), 1168-1174. https://doi.org/10.1007/s11606-011-1761-2.

Bowman, T. D. (2015). Investigating the use of affordances and framing techniques by scholars to manage personal and professional impressions on Twitter. Indiana University, Bloomington, IN.USA.

Braun, V., \& Clarke, V. (2006). Using thematic analysis in psychology. Qualitative Research in Psychology, 3(2), 77-101. https://doi.org/10.1191/1478088706qp063oa

Costas, R., Zahedi, Z., \& Wouters, P. (2015). Do "altmetrics" correlate with citations? Extensive comparison of altmetric indicators with citations from a multidisciplinary perspective. Journal of the Association for Information Science and Technology, 66(10), 2003-2019. Digital Libraries. https://doi.org/10.1002/asi.23309

Didegah, F., Mejlgaard, N., \& Sørensen, M. P. (2018). Investigating the quality of interactions and public engagement around scientific papers on Twitter. Journal of Informetrics, 12(3), 960-971. https://doi.org/10.1016/J.JOI.2018.08.002

Efron, M. (2011). Information search and retrieval in microblogs. Journal of the American Society for Information Science and Technology, 62(6), 996-1008. https://doi.org/10.1002/asi.21512

Enkhbayar, A., Haustein, S., Barata, G., \& Alperin, J. P. (2019). How much research shared on Facebook is hidden from public view? A comparison of public and private online activity around PLOS ONE papers. Retrieved from http://arxiv.org/abs/1909.01476

Farmer, A. D., Holt, C., Cook, M. J., \& Hearing, S. D. (2009). Social networking sites: a novel portal for communication. Postgraduate Medical Journal, 85(1007), 455-459. https://doi.org/10.1136/pgmj.2008.074674

Haustein, S. (2019). Scholarly Twitter metrics. In Glaenzel W, M. HF, U. Schmoch, \& M. Thelwall (Eds.), Handbook of Quantitative Science and Technology Research. Berlin: Springer. Retrieved from https://arxiv.org/abs/1806.02201

Haustein, S., Bowman, T. D., Holmberg, K., Tsou, A., Sugimoto, C. R., \& Larivière, V. (2014). Tweets as impact indicators: Examining the implications of automated bot accounts on Twitter. Journal of the Association for Information Science and Technology, 67(1), 232-238. Digital Libraries.

Haustein, S., Costas, R., \& Larivière, V. (2015). Characterizing social media metrics of scholarly papers: The effect of document properties and collaboration patterns. PLOS ONE, 10(3), 1-21. https://doi.org/10.1371/journal.pone.0120495

Haustein, S., Peters, I., Bar-Ilan, J., Priem, J., Shema, H., \& Terliesner, J. (2014). Coverage and adoption of altmetrics sources in the bibliometric community. Scientometrics, 101(2), 1145-1163. https://doi.org/10.1007/s11192-013-1221-3

Kalsnes, B., \& Larsson, A. O. (2018). Understanding News Sharing Across Social Media. Journalism Studies, 19(11), $1669-1688$. https://doi.org/10.1080/1461670X.2017.1297686 
Kamel Boulos, M. N., \& Anderson, P. F. (2012). Preliminary survey of leading general medicine journals' use of Facebook and Twitter 1. Journal of the Canadian Health Libraries Association, 33(02), 38-47. https://doi.org/10.5596/c2012-010

King, D. W., Tenopir, C., Choemprayong, S., \& Wu, L. (2009). Scholarly journal information-seeking and reading patterns of faculty at five US universities. Learned Publishing, 22(2), 126-144. https://doi.org/10.1087/2009208

Kortelainen, T., \& Katvala, M. (2012). "Everything is plentiful-Except attention" Attention data of scientific journals on social web tools. Journal of Informetrics, 6(4), 661-668. https://doi.org/10.1016/j.joi.2012.06.004

Kousha, K., \& Thelwall, M. (2008). Assessing the impact of disciplinary research on teaching: An automatic analysis of online syllabuses. Journal of the American Society for Information Science and Technology, 59(13), 2060-2069. https://doi.org/x

Kousha, K., \& Thelwall, M. (2016). An automatic method for assessing the teaching impact of books from online academic syllabi. Journal of the Association for Information Science and Technology, 67(12), 2993-3007. https://doi.org/10.1002/asi.23542

Larivière, V., Sugimoto, C. R., \& Bergeron, P. (2013). In their own image? a comparison of doctoral students' and faculty members' referencing behavior. Journal of the American Society for Information Science and Technology, 64(5), 10451054. https://doi.org/10.1002/asi.22797

Loeb, S., Bayne, C. E., Frey, C., Davies, B. J., Averch, T. D., Woo, H. H., ... Eggener, S. E. (2014). Use of social media in urology: data from the American Urological Association (AUA). BJU International, 113(6), 993-998. https://doi.org/10.1111/bju.12586

MacRoberts, M. H., \& MacRoberts, B. R. (1989). Problems of citation analysis: A critical review. Journal of the American Society for Information Science, 40(5), 342-349. https://doi.org/x

Madhusudhan, M. (2012). Use of social networking sites by research scholars of the University of Delhi: A study. The International Information \& Library Review, 44(2), 100-113. https://doi.org/10.1016/j.iilr.2012.04.006

McAlister, F. A., Graham, I., Karr, G. W., \& Laupacis, A. (1999). Evidence-based medicine and the practicing clinician. Journal of General Internal Medicine, 14(4), 236-242. https://doi.org/10.1046/j.1525-1497.1999.00323.x

Mohammadi, E. Barahmand, N., Thelwall,M. (2019): Who shares health and medical scholarly articles on Facebook?. figshare. Figures. https://doi.org/10.6084/m9.figshare.9784340.v1

Mohammadi, E., Thelwall, M., \& Kousha, K. (2016). Can Mendeley bookmarks reflect readership? A survey of user motivations. Journal of the Association for Information Science and Technology, 67(5). https://doi.org/10.1002/asi.23477

Mohammadi, E., Thelwall, M., Kwasny, M., \& Holmes, K. L. (2018). Academic information on Twitter: A user survey. PLoS ONE, 13(5). https://doi.org/10.1371/journal.pone.0197265

Mohammadi, E., Thelwall, M., Haustein, S., \& Larivière, V. (2015). Who reads research articles? An altmetrics analysis of Mendeley user categories. Journal of the Association for Information Science and Technology, 66(9), 1832-1846. https://doi.org/10.1002/asi.23286

Mohammadi, E., Thelwall, M., \& Kousha, K. (2016). Can Mendeley bookmarks reflect readership? A survey of user motivations. Journal of the Association for Information Science and Technology, 67(5), 1198-1209. https://doi.org/10.1002/asi.23477

Moran, M., Seaman, J., \& Group, H. T.-K.-B. S. R. (2011). Teaching, Learning, and Sharing: How Today's Higher Education Faculty Use Social Media. Pearson Learning Solutions and Babson Survey Research Group. Retrieved from https://eric.ed.gov/?id=ED535130

$\mathrm{Na}$, J. C., \& Ye, Y. E. (2017). Content analysis of scholarly discussions of psychological academic articles on Facebook. Online Information Review, 41(3), 337-353. https://doi.org/10.1108/OIR-02-2016-0058

National Institutes of Health. (2019). Imapct of NIH Research. Retrieved from https://www.nih.gov/about-nih/what-wedo/impact-nih-research

Nentwich, M., \& König, R. (2014). Academia Goes Facebook? The Potential of Social Network Sites in the Scholarly Realm. In Opening Science (pp. 107-124). Cham: Springer International Publishing. https://doi.org/10.1007/978-3-319-000268_7

Peruta, A., \& Shields, A. B. (2017). Social media in higher education: understanding how colleges and universities use Facebook. Journal of Marketing for Higher Education, 27(1), 131-143. https://doi.org/10.1080/08841241.2016.1212451

Perrin, A. \& Anderson, M. (2019). Share of U.S. adults using social media, including Facebook, is mostly unchanged since 2018, Pew Research Center, https://www.pewresearch.org/fact-tank/2019/04/10/share-of-u-s-adults-using-social-mediaincluding-facebook-is-mostly-unchanged-since-2018/

Preece, J., \& Maloney-Krichmar, D. (2005). Online Communities: Design, Theory, and Practice. Journal of Computer-Mediated Communication, 10(4), 00-00. https://doi.org/10.1111/j.1083-6101.2005.tb00264.x

Procter, R., Williams, R., Stewart, J., Poschen, M., Snee, H., Voss, A., \& Asgari-Targhi, M. (2010). Adoption and use of Web 2.0 in scholarly communications. Hilosophical Transactions of the Royal Society - Series A: Mathematical, Physical and Engineering Sciences, 368(1926), 4039-4056. https://doi.org/10.1098/rsta.2010.0155

Ringelhan, S., Wollersheim, J., \& Welpe, I. M. (2015). I like, I cite? Do Facebook likes predict the impact of scientific work? PLOS ONE, 1O(8), 1-21. https://doi.org/10.1371/journal.pone.0134389

Sarli, C. C., \& Holmes, K. L. (2012). The Becker Medical Library Model for Assessment of Research Impact. Retrieved from https://becker.wustl.edu/impact-assessment/

Schilling, L. M., Steiner, J. F., Lundahl, K., \& Anderson, R. J. (2005). Residents' patient-specific clinical questions: opportunities 
for evidence-based learning. Academic Medicine : Journal of the Association of American Medical Colleges, 80(1), 5156. Retrieved from http://www.ncbi.nlm.nih.gov/pubmed/15618093

Segado-Boj, F., Díaz-Campo, J., Fernández-Gómez, E., \& Chaparro-Domínguez, M.-Á. (2019). Spanish academics and social networking sites: Use, non-use, and the perceived advantages and drawbacks of Facebook, Twitter, Linkedln, ResearchGate, and Academia.edu. First Monday, 24(5). https://doi.org/10.5210/fm.v24i5.7296

Shema, H., Bar-Ilan, J., \& Thelwall, M. (2014). Do blog citations correlate with a higher number of future citations? Research blogs as a potential source for alternative metrics. Journal of the Association for Information Science and Technology, 65(5), 1018-1027. https://doi.org/10.1002/asi.23037

Sud, P., \& Thelwall, M. (2014). Evaluating altmetrics. Scientometrics, 98(2), 1131-1143. https://doi.org/10.1007/s11192-013$1117-2$

Tenopir, C., King, D. W., Clarke, M. T., Na, K., \& Zhou, X. (2007). Journal reading patterns and preferences of pediatricians. Journal of the Medical Library Association : JMLA, 95(1), 56-63. Retrieved from http://www.pubmedcentral.nih.gov/articlerender.fcgi?artid=1773049\&tool=pmcentrez\&rendertype=abstract

The Higher Education Funding Council for England (HEFCE). (2019). Guidance on submissions to REF 2021. Retrieved from https://www.ref.ac.uk/media/1092/ref-2019_01-guidance-on-submissions.pdf

Thelwall, M., Haustein, S., Larivière, V., \& Sugimoto, C. R. (2013). Do Altmetrics Work? Twitter and Ten Other Social Web Services. PLOS ONE, 8(5), e64841. https://doi.org/10.1371/journal.pone.0064841

Tsou, A., Bowman, T., Ghazinejad, A., \& Sugimoto, C. (2015). Who tweets about science ? In Proceedings of the 2015 International Society for Scientometrics and Informetrics. (pp. 95-100). Istanbul, Turkey.

Vainio, J., \& Holmberg, K. (2017). Highly tweeted science articles: who tweets them? An analysis of Twitter user profile descriptions. Scientometrics, 112(1), 345-366. https://doi.org/10.1007/s11192-017-2368-0

$\mathrm{Yu}, \mathrm{H}$. (2017). Context of altmetrics data matters: an investigation of count type and user category. Scientometrics, 111(1), 267-283. https://doi.org/10.1007/s11192-017-2251-z

Zahedi, Z., Costas, R., \& Wouters, P. (2014). How well developed are altmetrics? A cross-disciplinary analysis of the presence of 'alternative metrics' in scientific publications. Scientometrics, 101(2), 1491-1513. https://doi.org/10.1007/s11192014-1264-0

Zahedi, Z., Fenner, M., \& Costas, R. (2014). How consistent are altmetrics providers? Study of 1000 PLOS ONE publications using the PLOS ALM, Mendeley and Altmetric.com APIs. In altmetrics 14. Workshop at the Web Science Conference, Bloomington, IN. https://doi.org/10.6084/m9.figshare.1041821.v2

Zedda, M., \& Barbaro, A. (2015). Adoption of Web 2.0 tools among STM publishers. How social are scientific journals? Journal of the European Association for Health Information and Libraries, 11, 9-12. 